\title{
Torsion of Gravid Uterus due to Uterine Asymmetry associated with Placental Abruption, Intrauterine Fetal Demise, and Maternal Shock
}

\author{
Ashakiran Thavarsingh Rathod
}

\begin{abstract}
A 24-year-old gravida 3 para 2 living 1 with 28 weeks gestation presented with acute abdomen and shock. A diagnosis of concealed abruption with intrauterine death of fetus was made and case was taken for emergency cesarean section. It turned out to be $180^{\circ}$ levorotation of gravid uterus with abruption. Detorsion of the uterus failed. A dead fetus was delivered through a vertical incision on posterior wall of uterus. Asymmetrically, enlarged uterus and excess liquor were the associated findings. Total hysterectomy was done for uncontrolled atonic postpartum hemorrhage. Postoperative period was uneventful. Although a rare obstetric condition, torsion of gravid uterus should be considered in the differential diagnosis of placental abruption particularly when concealed.
\end{abstract}

Keywords: Torsion, Gravid uterus, Abruption, Shock, Intrauterine fetal demise.

How to cite this article: Rathod AT. Torsion of Gravid Uterus due to Uterine Asymmetry associated with Placental Abruption, Intrauterine Fetal Demise and Maternal Shock. Int J Infertil Fetal Med 2014;5(2):64-65.

Source of support: Nil

Conflict of interest: None

Date of Received: 29-06-14

Date of Acceptance: 17-07-14

Date of Publication: May 2014

\section{INTRODUCTION}

Uterine torsion defined as rotation greater than $45^{\circ}$ around the long axis, was first described in 1983 by virchow. ${ }^{1} \mathrm{~A}$ 1992 world literature review found only 212 reported cases of torsion of the gravid uterus. ${ }^{2}$ Torsion of pregnant uterus is an unusual complication of pregnancy. Abnormal presentation, myomatous uterus, uterine malformations and pelvic adhesions are the abnormalities associated with uterine torsion. ${ }^{2}$ The diagnosis is usually established only after opening the abdomen or even after closure of the uterine incision. ${ }^{3}$

\section{Assistant Professor}

Department of Obstetrics and Gynecology, Bangalore Medical College and Research Institute, Bengaluru, Karnataka, India

Corresponding Author: Ashakiran Thavarsingh Rathod Assistant Professor, Department of Obstetrics and Gynecology Bangalore Medical College and Research Institute, Bengaluru Karnataka, India, Phone: 9845041084 , e-mail: tr.ashakiran@ gmail.com

\section{CASE REPORT}

A 24-year-old gravida 3 para 2 living 1 with 28 weeks gestation presented with pain abdomen of abrupt onset when she was sleeping in the midnight. She came to our hospital after 10 hours in shock. On examination, she was conscious but disoriented. She was pale, pulse was feeble, heart rate was 110 per minute and blood pressure was not recordable. Per abdomen examination showed uterus of 32 weeks size, tense and tender. On per vaginal examination, cervix was $2 \mathrm{~cm}$ long uneffaced with closed os. Bed side ultrasound revealed absent fetal heart. A diagnosis of concealed abruption was made. Patient was resuscitated. Decision to do an emergency cesarean was taken in view of unfavorable cervix and poor maternal condition. Investigations showed hemoglobin $6.3 \mathrm{gm} / \mathrm{dl}$, hematocrit $16.9 \%$ and platelet count of $71000 / \mu 1$.

\section{Operative Findings}

Laparotomy was done under general anesthesia. Uterus was bluish green in color. Gravid uterus of 32 weeks size, levorotated to $180^{\circ}$ was seen. Left fallopian tube and ovary were on the right side and the right fallopian tube and ovary on left side. The crossing of right round ligament was seen in the midline (Fig. 1). Both ovaries were anterior to the uterus (Fig. 2). There were engorged veins on the uterus. Diagnosis of torsion was made. Attempt to rotate the uterus failed and lower uterine segment was very narrow and twisted. So an upper segment vertical incision

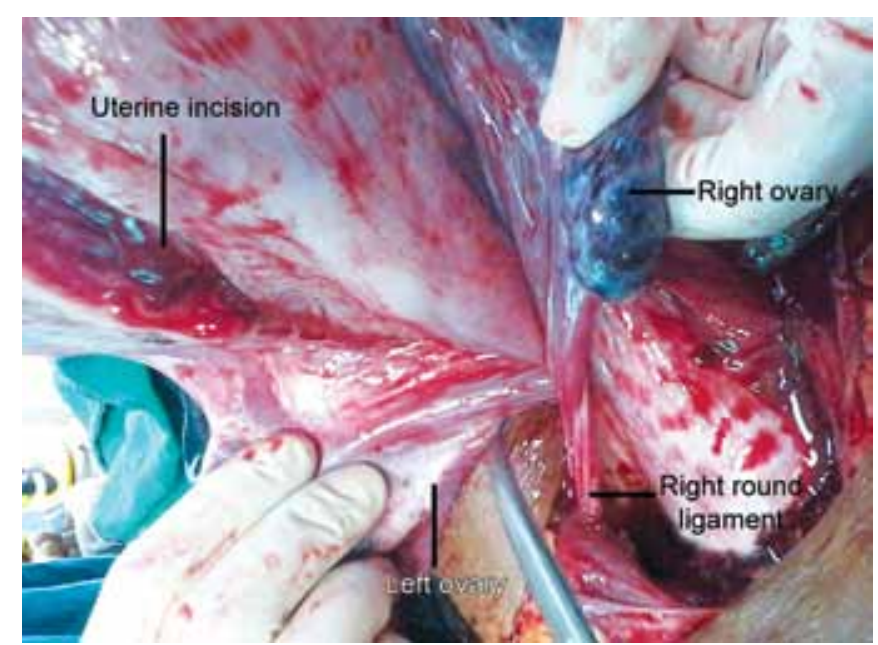

Fig. 1: Torsion of $180^{\circ}$ 


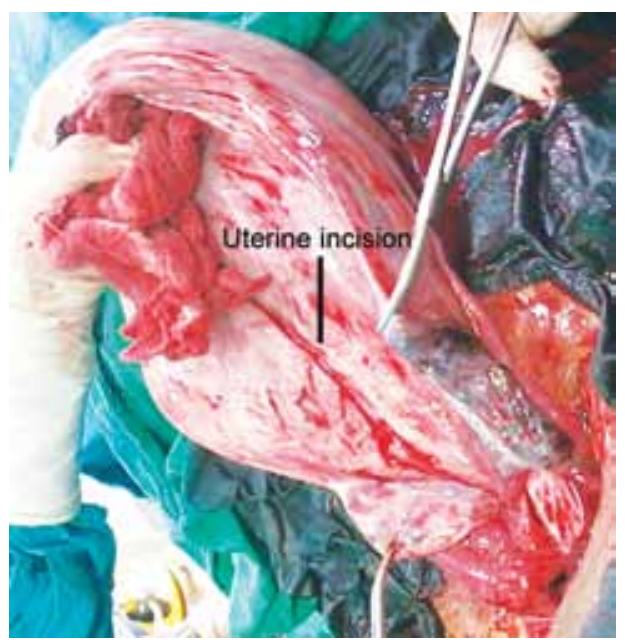

Fig. 2: Cesarean done through a posterior upper segment vertical incision

was made on the posterior wall of uterus which was now anterior. Liquor of around $2 \mathrm{~L}$ drained. Dead male fetus of $1.5 \mathrm{~kg}$ was extracted by breech. Retroplacental clots of $500 \mathrm{gm}$ removed. Uterus rotated back. Uterus was asymmetrically enlarged (Fig. 3). Right half of uterus was more enlarged and was tense and cystic with the uterine wall thinned out. The left half of the uterus had thick wall. Uterus was atonic, not contracting with uterotonics. Patient continued to have bleeding from the uterine cavity. Bimanual compression failed to stop bleeding. Patient's vitals started deteriorating. Hence, decision to do hysterectomy was taken. Total hysterectomy was done. A total of 4 units of packed cells, 6 units of fresh frozen plasma and 6 units of platelets were transfused. Postoperative period was uneventful, and patient was discharged on 9th postoperative day in good condition.

\section{DISCUSSION}

Torsion of gravid uterus is very rare. In this case, correct diagnosis was not made before laparotomy. The reports of all cases published so far show that torsion was recognized only at laparotomy. In this case, the torsion can be explained because of asymmetrical enlargement of the uterus. Excess liquor may be an additional factor. The enlarged part of the uterus was very tense and thin walled because of excess liquor. There was also placental abruption in this case. Torsion likely caused placental abruption by causing engorgement and high pressure within the uterine wall. Because of torsion, the hemorrhage from abruption was concealed and not allowed to escape. Alternatively, abruption could have

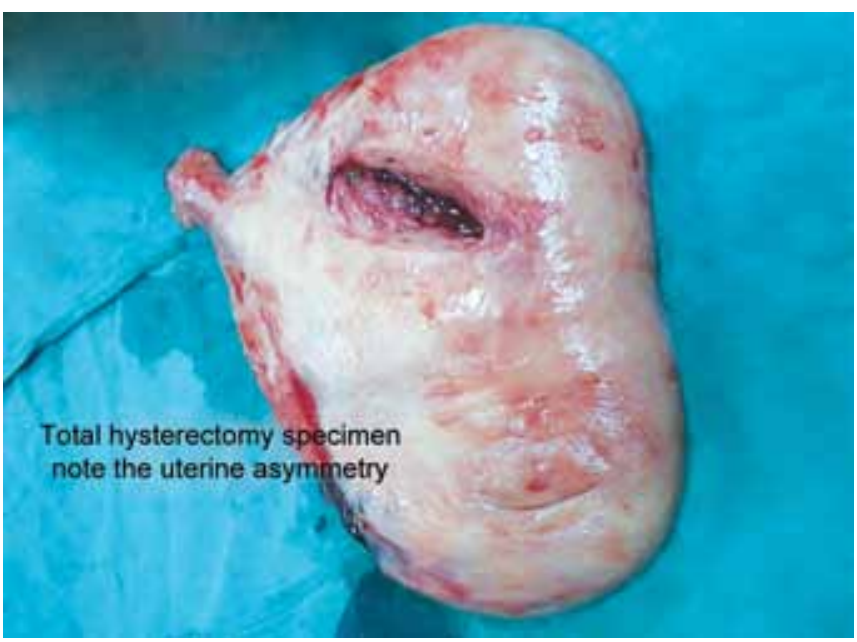

Fig. 3: Specimen after total hysterectomy

resulted in further increase in the weight of the enlarged part of uterus leading to torsion. This patient presented with shock, the severity of which was greater than expected for the initial hemoglobin level.

Treatment of torsion of gravid uterus is laparotomy, detorsion of the uterus and cesarean section. ${ }^{4}$ When detorsion is not possible, a low transverse posterior incision has been described to deliver the baby, but there is risk of damage to the ureters. ${ }^{5}$ Vertical incision in the posterior upper segment is safer, although the effects of this incision on future pregnancies are unknown. ${ }^{6}$

\section{CONCLUSION}

Although a rare obstetric condition, torsion of gravid uterus should be considered in the differential diagnosis of placental abruption particularly when concealed.

\section{REFERENCES}

1. Biswas MK, Summers P, Schultis SA, Herrera EH, Pernoll ML. Torsion of gravid uterus: a report of two cases. J Reprod Med 1990;35(2):194-197.

2. Jenson JG. Uterine torsion in pregnancy. Acta Obstet Gynecol Scand 1992;71(4):260-265.

3. Visser AA, Giesteria MV, Heyns A, Marias C. Torsion of gravid uterus: case reports. Br J Obstet Gynaecol 1983;90(1):87-99.

4. Fait G, Grisaru D, Gull I. Torsion of pregnant uterus at term. Int J Gyn Obs 1997;59(1):41-42.

5. Mustafa MS, Shakeel F, Sporrong B. Extreme torsion of pregnant uterus. Aust NZ J Obstet Gynecol 1999;39(3):360-363.

6. Olah KS. Classical cesarean section through the posterior uterine wall: a complication of complete uterine torsion. J Obstet Gynecol 1996;16(1):32-33. 